\title{
Evaluation of the hemodynamics and right ventricular function in pulmonary hypertension by echocardiography compared with right-sided heart catheterization
}

\author{
YIDAN LI, YIDAN WANG, HONG LI, WEIWEI ZHU, XIANGLI MENG and XIUZHANG LU \\ Department of Echocardiography, Heart Center, Beijing Chao Yang Hospital, \\ Capital Medical University, Beijing 100020, P.R. China
}

Received April 12, 2016 Accepted March 17, 2017

DOI: $10.3892 /$ etm.2017.4953

\begin{abstract}
The present study aimed to evaluate hemodynamics and right ventricular function in patients with pulmonary hypertension $(\mathrm{PH})$ using transthoracic echocardiography and to compare these results with measurements obtained using right-sided heart catheterization (RHC). A total of 75 patients with PH were examined using echocardiography and RHC. Patients were divided into the following two groups according to their difference between $\mathrm{SPAP}_{\text {echo }}$ and $\mathrm{SPAP}_{\mathrm{RHC}}$ measurement: The overestimated group and underestimated group. The overestimated group included the subgroups group over-A $_{\text {(differ- }}$ ence $<20 \mathrm{mmHg}$ ) and group ${ }_{\text {over-B }}$ (difference $\geq 20 \mathrm{mmHg}$ ), and the underestimated group included group under-A $_{\text {(absolute }}$ value of the difference $<20 \mathrm{mmHg}$ ) and group under-B $_{\text {(absolute }}$ value of the difference $\geq 20 \mathrm{mmHg}$ ). SPAP $_{\text {echo }}$ measurements were revealed to be significantly positively correlated with SPAP $_{\mathrm{RHC}}$ measurements $(\mathrm{r}=0.794 ; \mathrm{P}<0.01)$. Among all echocardiographic measurements, only tricuspid annular plane systolic excursion (TAPSE) was significantly different between groups; it was increased in group ${ }_{\text {over-A }}$ and group under-A $_{\text {A }}$ compared with group ${ }_{\text {over-B }}(\mathrm{P}<0.01)$. Although SPAP measurements obtained using echocardiography were significantly positively correlated with those obtained using RHC, a high proportion of overestimation or underestimation of SPAP by echocardiography remained.
\end{abstract}

Correspondence to: Professor Yidan Li or Professor Xiuzhang Lu, Department of Echocardiography, Heart Center, Beijing Chao Yang Hospital, Capital Medical University, 8 Gongren Tiyuchang Nanlu, Chaoyang, Beijing 100020, P.R. China

E-mail: yidan_li@163.com

E-mail: chaoyanglxz@163.com

Key words: echocardiography, hypertension, pulmonary, hemodynamics

\section{Introduction}

Pulmonary hypertension (PH) is characterized by an increased pressure in the pulmonary arteries, leading to increased right-sided heart load and dysfunction (1-3). PH is diagnosed by a mean pulmonary artery pressure (mPAP) $\geq 25 \mathrm{mmHg}$ measured during right-sided heart catheterization (RHC) at rest whilst at sea level (4). PH is a hemodynamic condition caused by a variety of diseases of the lungs and heart, or other systemic diseases (5-8). RHC remains the primary standard for the evaluation of $\mathrm{PH}$, with the ability to exclude left-to-right cardiac shunt and other severe left-sided heart conditions $(9,10)$. However, RHC is invasive and has potentially fatal complications (11). Therefore, various noninvasive methods have been used to diagnose $\mathrm{PH}$, including echocardiography, magnetic resonance imaging and nuclear imaging (12-19). Transthoracic echocardiography is a promising method for the evaluation of $\mathrm{PH}$, and right-sided heart structure and function $(20,21)$. A previous study demonstrated that systolic pulmonary arterial pressure (SPAP) and mPAP measured during RHC are similar to measurements obtained by echocardiography (22). However, concerns regarding the accuracy of echocardiography for measuring SPAP remain (23-26).

In the present study, the clinical data of 75 patients with $\mathrm{PH}$ were enrolled and the results of echocardiography were compared with those of RHC. Factors that affect the accuracy of echocardiography in the evaluation of $\mathrm{PH}$ were analyzed and discussed.

\section{Materials and methods}

Patients. Between August 2011 and December 2014, a total of 92 patients with clinical manifestations of $\mathrm{PH}$ were enrolled in the present study, recruited from the Heart Center of Beijing Chao Yang Hospital (Beijing, China). Among these patients, 17 were excluded due to contraindications such as severe arrhythmias, renal inadequacy, and serious heart failure. Therefore, a total of 75 patients with $\mathrm{PH}$ were included in the present study. Among these 75 patients, 22 were male and 53 were female, with a mean age of $46.8 \pm 12.5$ years. The present study followed the guidelines of the Declaration of Helsinki and was approved by the Ethics Committee of Beijing Chao 
Yang Hospital (Beijing, China). Written informed consent was obtained from all participants.

Echocardiographic measurements. Echocardiography to measure SPAP (SPAP ${ }_{\text {echo }}$ ) was performed using Philips iE33 (Philips Healthcare, DA Best, The Netherlands) and Toshiba Artida (Toshiba Medical Systems, Tochigi, Japan) Doppler ultrasound machines with S4 and PST-30SBT transducers, respectively $(2.5-3.5 \mathrm{MHz})$. The lead II electrocardiogram was recorded synchronously. The patients were placed into a left lateral position or supine position for measurements. The inner diameter of the main pulmonary artery was measured in the short axis view of the great vessels. Left ventricular ejection fraction was measured using the Simpson's method (27). The tricuspid regurgitation area was measured in an apical four chamber view. To evaluate RV function, the RV index of myocardial performance (RIMP), tricuspid annular plane systolic excursion (TAPSE), RV fractional area change (RVFAC), and tricuspid annular systolic velocity (s') were included. Images of the RV-focused apical four-chamber view were obtained for further analysis, and TAPSE was acquired in M-mode. Systolic displacement was measured from end-diastole to end-systole. Furthermore, RV end-diastolic area (RV EDA) and RV end-systolic area (RV ESA) were obtained by two-dimensional echocardiography. The RVFAC was calculated as: (RV diastolic area-RV systolic area)/RV diastolic area $\mathrm{x} 100 \%$. The tricuspid s' was measured by tissue Doppler imaging in the apical four-chamber view. RIMP was calculated as the ratio of isovolumic time to ejecting time, which was measured during pulsed tissue Doppler imaging. The ratio of the RV transverse diameter to the left ventricular transverse diameter was obtained at the end of diastole using the apical four chamber view.

RHC procedure. A Swan-Ganzcatheter(Edwards Lifesciences, Irvine, CA, USA) was inserted through the internal jugular vein into the right inferior pulmonary artery. The following parameters were measured after hemodynamics had stabilized: SPAP (SPAP $\left.{ }_{\mathrm{RHC}}\right)$, mPAP, central venous pressure (CVP) and pulmonary vascular resistance. For each patient, echocardiography and RHC were performed with an interval of $<48 \mathrm{~h}$. All echocardiography and RHC measurements were repeated three times, and the mean value was calculated.

Patients were divided into two groups according to the difference between SPAP $_{\text {echo }}$ and $\mathrm{SPAP}_{\mathrm{RHC}}$, an overestimated group and underestimated group. The overestimated group included the subgroups group ${ }_{\text {over-A }}$ (difference, $<20 \mathrm{mmHg}$ )

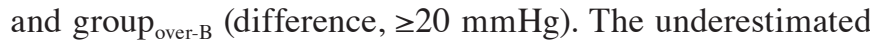
group included the subgroups group ${ }_{\text {under-A }}$ (absolute value of the

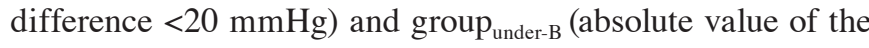
difference $\geq 20 \mathrm{mmHg}$ ).

Statistical analysis. All data are presented as the mean \pm standard deviation. Comparisons between groups were made using independent sample t-tests and comparison between the overestimated and underestimated subgroups were made using one-way analysis of variance followed by a Fisher's least significant difference test. SPAP ${ }_{\text {echo }}$ and $\mathrm{SPAP}_{\mathrm{RHC}}$ were analyzed using Pearson correlation coefficient analysis and a Bland-Altman plot. All statistical analyses were performed

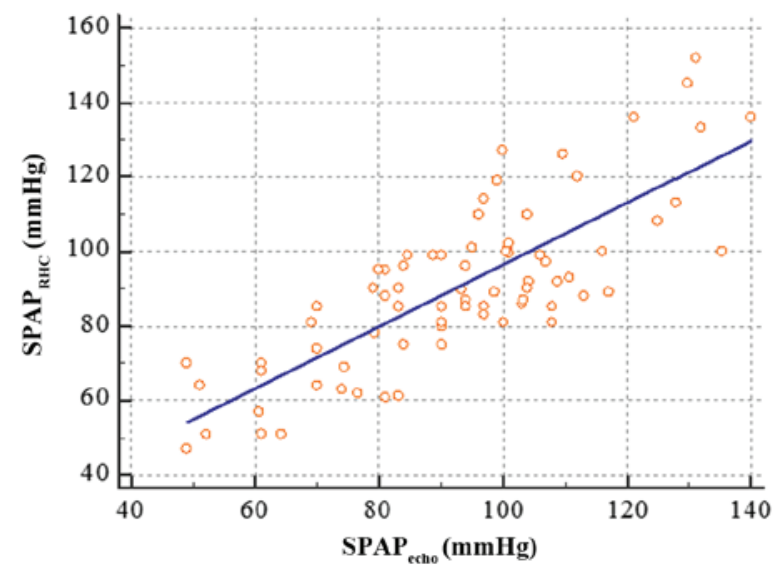

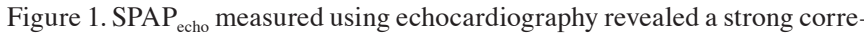
lation with $\mathrm{SPAP}_{\mathrm{RHC}}$ measured using RHC. $r=0.794 ; \mathrm{P}<0.01$. SPAP, systolic pulmonary arterial pressure; RHC, right heart catheterization.

using SPSS software (version 17.0; SPSS, Inc., Chicago, IL, USA). $\mathrm{P}<0.05$ was considered to indicate a statistically significant difference.

\section{Results}

Patient clinicopathological characteristics. According to the 2003 World Health Organization PH classification criteria (28), there were 39 cases of pulmonary arterial hypertension (PAH) and 36 cases of chronic thromboembolic pulmonary hypertension in the present study (Table I). The etiologies of PAH included idiopathic PAH in 26 cases, connective tissue disease in 9 cases, congenital heart disease in 2 cases, portal hypertension in 1 case and hereditary $\mathrm{PAH}$ in 1 case, data not shown.

Positive correlation between RHC and echocardiography measurements. There was a significant positive correlation between $\mathrm{SPAP}_{\text {echo }}$ measured using tricuspid regurgitation and SPAP $_{\text {RHC }}$ measured using RHC ( $r=0.794 ; \mathrm{P}<0.01$; Fig. 1). In addition, a Bland-Altman plot revealed agreement between

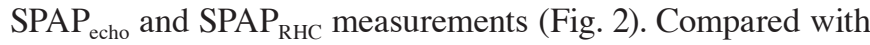
$\mathrm{SPAP}_{\mathrm{RHC}}, \mathrm{SPAP}_{\text {echo }}$ was overestimated in 23 patients (overestimated group, $30.7 \%$ ), in which 16 patients were in group over-A $_{\text {A }}$ and 7 patients were in group over-B $_{\text {(Table II). SPAP }}$ echo was underestimated in 18 patients (underestimated group, 24\%) compared with $\mathrm{SPAP}_{\mathrm{RHC}}$, with 14 patients in group under-A $_{\text {and }}$ 4 patients were in group under-B (Table II).

Among all echocardiographic measurements taken in the present study, only TAPSE was significantly increased in group $_{\text {over-A }}$ and group under-A $_{\text {compared with group }}$ over-B $(\mathrm{P}<0.01$; Table II). Among the RHC measurements, CVP was significantly decreased in group ${ }_{\text {over-A }}$ compared with group $_{\text {over-B }}(\mathrm{P}<0.05)$, while mPAP was significantly increased in group under-A $(\mathrm{P}<0.01)$ and group under-B $(\mathrm{P}<0.05)$ compared with group $_{\text {over-A }}($ Table III). An electrocardiography SPAP cut-off value of $\geq 50 \mathrm{mmHg}$ demonstrated good sensitivity (98.64\%) and specificity (100\%) for $\mathrm{PH}$, in addition to a good positive $(100 \%)$ and negative $(50 \%)$ predictive value (Table IV).

A 36-year-old female with pulmonary hypertension was presented, in which tricuspid regurgitation velocity was from 
Table I. Patient characteristics.

\begin{tabular}{|c|c|c|c|}
\hline \multirow[b]{2}{*}{ Clinical characteristics } & \multicolumn{2}{|c|}{ Type of PH } & \multirow[b]{2}{*}{ P-value } \\
\hline & CTEPH $(n=36)$ & PAH $(n=39)$ & \\
\hline \multicolumn{4}{|l|}{ General information } \\
\hline Age, years & $52.03 \pm 12.33$ & $42.03 \pm 10.72$ & 0.001 \\
\hline Body mass index, $\mathrm{kg} / \mathrm{m}^{2}$ & $25.89 \pm 4.88$ & $23.26 \pm 3.82$ & 0.011 \\
\hline Heart rate, beats/min & $79.14 \pm 18.81$ & $81.29 \pm 11.04$ & 0.702 \\
\hline $\mathrm{SBP}, \mathrm{mmHg}$ & $117.71 \pm 15.12$ & $109.61 \pm 21.65$ & 0.094 \\
\hline $\mathrm{DBP}, \mathrm{mmHg}$ & $76.48 \pm 10.25$ & $70.01 \pm 15.74$ & 0.074 \\
\hline 6 min walk distance, $\mathrm{m}$ & $378.09 \pm 90.89$ & $360.60 \pm 102.37$ & 0.030 \\
\hline \multicolumn{4}{|l|}{ Hemodynamic parameters } \\
\hline $\mathrm{SPAP}_{\mathrm{RHC}}$ & $90.28 \pm 12.13$ & $90.33 \pm 28.52$ & 0.992 \\
\hline mPAP, $\mathrm{mmHg}$ & $49.61 \pm 9.72$ & $54.21 \pm 18.48$ & 0.188 \\
\hline PCWP, mmHg & $9.22 \pm 4.82$ & $8.51 \pm 4.77$ & 0.524 \\
\hline PVR, dyn $\cdot S \cdot \mathrm{cm}^{-5}$ & $1,046.00 \pm 394.87$ & $1,227.40 \pm 616.78$ & 0.141 \\
\hline \multicolumn{4}{|l|}{ Echocardiographic structure } \\
\hline RVTD & $48.75 \pm 10.11$ & $45.70 \pm 8.80$ & 0.180 \\
\hline LVTD & $31.51 \pm 4.13$ & $30.28 \pm 6.11$ & 0.359 \\
\hline $\mathrm{D}_{\mathrm{MPA}}$ & $31.75 \pm 3.91$ & $32.19 \pm 4.79$ & 0.669 \\
\hline $\mathrm{D}_{\mathrm{RPA}}$ & $23.28 \pm 3.00$ & $21.17 \pm 2.63$ & 0.003 \\
\hline $\mathrm{D}_{\mathrm{LPA}}$ & $22.02 \pm 2.56$ & $20.30 \pm 3.52$ & 0.029 \\
\hline \multicolumn{4}{|l|}{ Echocardiographic function } \\
\hline LVEF & $72.29 \pm 6.99$ & $73.36 \pm 6.45$ & 0.502 \\
\hline $\mathrm{SPAP}_{\text {echo }}$ & $92.99 \pm 17.09$ & $92.35 \pm 24.47$ & 0.896 \\
\hline TAPSE & $13.18 \pm 2.72$ & $14.275 \pm 1.95$ & 0.124 \\
\hline RIMP & $0.92 \pm 0.27$ & $0.91 \pm 0.29$ & 0.925 \\
\hline FAC & $26.68 \pm 6.95$ & $26.53 \pm 7.81$ & 0.942 \\
\hline$s^{\prime}$ & $9.57 \pm 1.75$ & $10.41 \pm 2.25$ & 0.198 \\
\hline
\end{tabular}

CTEPH, chronic thromboembolic pulmonary hypertension; PAH, pulmonary arterial hypertension; SBP, systolic blood pressure; DBP, diastolic blood pressure; SPAP, systolic pulmonary arterial pressure; RHC, right heart catheterization; mPAP, mean pulmonary arterial pressure; PCWP, pulmonary capillary wedge pressure; PVR, pulmonary vascular resistance; RVTD, right ventricular transverse diameter; LVTD, left ventricular transverse diameter; $\mathrm{D}_{\mathrm{MPA}}$, diameter of main pulmonary artery; $\mathrm{D}_{\mathrm{LPA}}$, diameter of left arterial branch; $\mathrm{D}_{\mathrm{RPA}}$, diameter of right pulmonary arterial branch; LVEF, left ventricular ejection fraction; echo, echocardiography; TAPSE, tricuspid annular plane systolic excursion; RIMP, RV index of myocardial performance; FAC, right ventricular fractional area change; s', tissue Doppler-derived tricuspid lateral annular systolic velocity.

Table II. Comparison of echocardiographic measurements between groups.

\begin{tabular}{lclllrrr}
\hline Group & No. of patients & TAPSE, mm & FAC, $\%$ & RIMP & s', cm/sec & $\mathrm{A}_{\mathrm{TR}}, \mathrm{cm}^{2}$ & SPAP \\
\hline Group $_{\text {over-A }}$ & 16 & $14.11 \pm 2.15^{\mathrm{a}}$ & $24.46 \pm 6.74$ & $0.87 \pm 0.21$ & $10.33 \pm 1.94$ & $8.20 \pm 5.84$ & $96.33 \pm 19.82$ \\
Group $_{\text {over-B }}$ & 7 & $10.41 \pm 2.07$ & $29.31 \pm 2.09$ & $0.80 \pm 0.16$ & $9.33 \pm 2.16$ & $13.25 \pm 5.58$ & $93.01 \pm 16.94$ \\
Group $_{\text {under-A }}$ & 14 & $14.81 \pm 2.51^{\mathrm{a}}$ & $28.26 \pm 11.02$ & $0.88 \pm 0.32$ & $10.98 \pm 1.91$ & $5.53 \pm 2.75$ & $83.91 \pm 20.92$ \\
Group $_{\text {under-B }}$ & 4 & $13.30 \pm 1.93$ & $27.73 \pm 4.24$ & $1.02 \pm 0.19$ & $9.47 \pm 3.42$ & $10.53 \pm 7.59$ & $93.00 \pm 26.39$ \\
\hline
\end{tabular}

${ }^{\mathrm{a}} \mathrm{P}<0.05$ vs. group ${ }_{\text {over-B. }}$. TAPSE, tricuspid annular plane systolic excursion; FAC, right ventricular fractional area change; RIMP, RV index of myocardial performance; s', tissue Doppler-derived tricuspid lateral annular systolic velocity; $\mathrm{A}_{\mathrm{TR}}$, tricuspid regurgitation area; SPAP, systolic pulmonary arterial pressure; echo, echocardiography.

415.9-482.7 $\mathrm{cm} / \mathrm{sec}$ and the $\mathrm{PG}$ was from $69.2-93.2 \mathrm{mmHg}$ as measured by contrasted echocardiography. A low level of tricuspid regurgitation may lead to an incomplete Doppler spectrum and underestimation of SPAP, and may be solved by using contrast bubbles in the right side of the heart (Fig. 3). A 61-year-old female with pulmonary hypertension was also 
Table III. Comparison of right-sided heart catheterization measurements between groups.

\begin{tabular}{lrccrr}
\hline Group & $\mathrm{n}$ & $\mathrm{CVP}, \mathrm{mmHg}$ & $\mathrm{SPAP}_{\mathrm{RHC}}, \mathrm{mmHg}$ & $\mathrm{mPAP}, \mathrm{mmHg}$ & $\mathrm{PVR}, \mathrm{dyn} \cdot \mathrm{S} \cdot \mathrm{cm}^{-5}$ \\
\hline Group $_{\text {over-A }}$ & 16 & $4.38 \pm 3.48$ & $80.81 \pm 19.70$ & $44.94 \pm 9.06$ & $1,081.25 \pm 492.65$ \\
Group $_{\text {over-B }}$ & 7 & $9.71 \pm 6.37^{\mathrm{a}}$ & $71.43 \pm 16.38$ & $43.71 \pm 11.10$ & $933.29 \pm 389.24$ \\
Group $_{\text {under-A }}$ & 14 & $7.71 \pm 5.12$ & $98.79 \pm 21.70^{\mathrm{a}}$ & $62.29 \pm 20.46^{\mathrm{b}}$ & $1,367.50 \pm 670.31$ \\
Group $_{\text {under-B }}$ & 4 & $9.25 \pm 8.77$ & $117.25 \pm 24.49^{\mathrm{b}}$ & $61.75 \pm 15.09^{\mathrm{a}}$ & $1,260.25 \pm 416.64$ \\
\hline
\end{tabular}

${ }^{\mathrm{a}} \mathrm{P}<0.05,{ }^{\mathrm{b}} \mathrm{P}<0.01$ vs. group ${ }_{\text {over-A }}$. CVP, central venous pressure; SPAP, systolic pulmonary arterial pressure; mPAP, mean pulmonary arterial pressure; PVR, pulmonary vascular resistance.

Table IV. Sensitivity, specificity and diagnostic accuracy of noninvasive assessment of pulmonary hypertension by Doppler echocardiography at various cut-off levels.

\begin{tabular}{lcccc}
\hline Cut-off & $\begin{array}{c}\text { Specificity, } \\
\%\end{array}$ & $\begin{array}{c}\text { Specificity, } \\
\%\end{array}$ & $\begin{array}{c}\text { PPV, } \\
\%\end{array}$ & $\begin{array}{c}\text { NPV, } \\
\%\end{array}$ \\
\hline SPAP, mmHg & 98.64 & 100 & 100 & 50.00 \\
$\geq 70$ & 95.16 & 53.85 & 90.77 & 70.00 \\
$\geq 90$ & 80.00 & 57.50 & 62.22 & 76.67 \\
\hline
\end{tabular}

SPAP, systolic pulmonary arterial pressure; PPV, positive predictive value; NPV, negative predictive value.

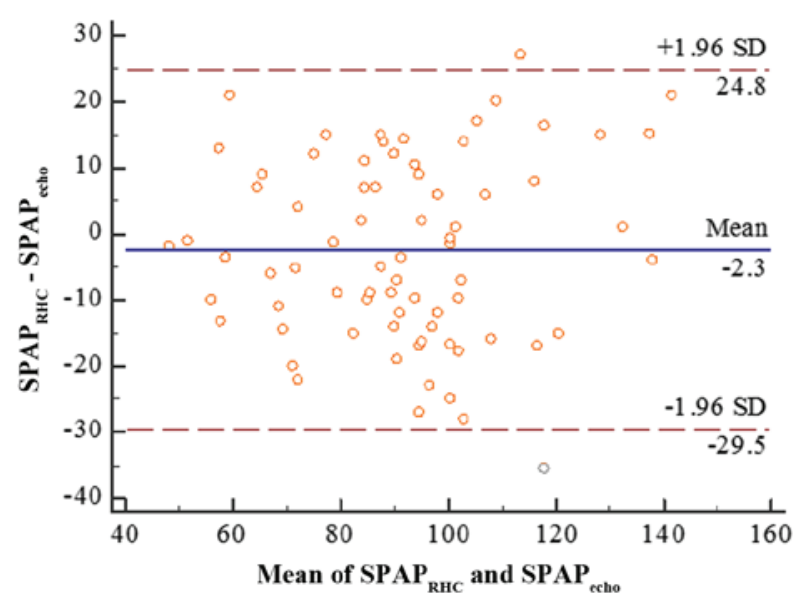

Figure 2. Bland-Altman plot of $\mathrm{SPAP}_{\text {echo }}$ measured using echocardiography and $\mathrm{SPAP}_{\mathrm{RHC}}$ measured using RHC. SPAP, systolic pulmonary arterial pressure; RHC, right heart catheterization; SD, standard deviation.

presented; echocardiography revealed intermediate to severe tricuspid regurgitation with a velocity of $500 \mathrm{~cm} / \mathrm{sec}$ and a PG of $99.8 \mathrm{mmHg}$. Follow up 3 years later, revealed severe tricuspid regurgitation with a velocity of $232 \mathrm{~cm} / \mathrm{sec}$ and a PG of $21.6 \mathrm{mmHg}$ (Fig. 4). Finally, a 33-year-old male with pulmonary hypertension was presented. During inspiration, tricuspid regurgitation velocity was $480.4 \mathrm{~cm} / \mathrm{sec}$ with a PG of $92.3 \mathrm{mmHg}$. During expiration, the tricuspid regurgitation velocity was $584.9 \mathrm{~cm} / \mathrm{sec}$ with a PG of $136.8 \mathrm{mmHg}$. At the end of expiration, tricuspid regurgitation velocity was $496.7 \mathrm{~cm} / \mathrm{sec}$ with a PG of $98.7 \mathrm{mmHg}$. (Fig. 5).

\section{Discussion}

RHC is the reference method and 'gold standard' for the quantification of SPAP; however, the noninvasive assessment of SPAP by Doppler echocardiography is feasible and represents a potential examination to conduct in patients with suspected PH. Conclusions derived from an echocardiographic examination should aim to assign a level of probability to a diagnosis of $\mathrm{PH}$. Echocardiography may also aid in detecting the cause of suspected or confirmed PH (29). The present study demonstrated a significant positive correlation and good agreement between Doppler echocardiography and RHC measurements. A detailed literature analysis by Finkelhor et al (30) demonstrated that the SPAP ${ }_{\text {echo }}$ correlates well with SPAP $_{\mathrm{RHC}}$ values in patients with left-sided heart pathology, whereas it does not correlate as well in right-sided heart pathology. Further information is required to explain these disparate results.

In the present study, $\mathrm{PH}$ with a systolic pulmonary artery pressure $\geq 50 \mathrm{mmHg}$ was estimated invasively by RHC, confirming that tricuspid regurgitation could exclude PH. SPAP may be evaluated using echocardiography and tricuspid regurgitation according to the simplified Bernoulli equation (31) (tricuspid regurgitation pressure gradient+right atrium pressure). A low level of tricuspid regurgitation may lead to an incomplete Doppler spectrum and underestimation of SPAP $(31,32)$. This problem may be solved by using contrast bubbles in the right side of the heart. A study by Jeon et al (32) demonstrated that contrasted echocardiography using a $10 \%$ air, $10 \%$ blood and $80 \%$ saline mixture had a high correlation with RHC measurements. By contrast, in patients with severe tricuspid regurgitation or right-sided heart failure, evaluation of SPAP using tricuspid regurgitation is prone to underestimation. Under these conditions, due to the neglect of inertial factors in the simplified Bernoulli equation, the pressure gradient between the right atrium and ventricle is underestimated, causing truncation of the tricuspid regurgitation spectrum.

Intrathoracic pressure and respiration affects the accuracy of tricuspid regurgitation pressure gradient measurement (33). During inspiration, RV pressure is decreased, leading to increased blood return and filling of the RV in diastole. This increases RV contraction and tricuspid regurgitation velocity. However, in patients with right-sided heart failure, increased filling of the right side of the heart during diastole does not increase RV contraction; therefore, the regurgitation velocity 
A

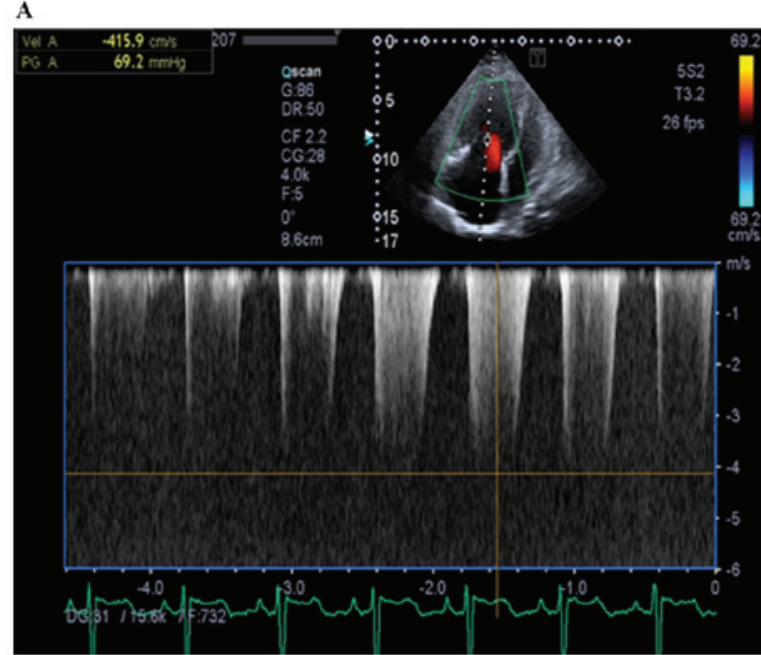

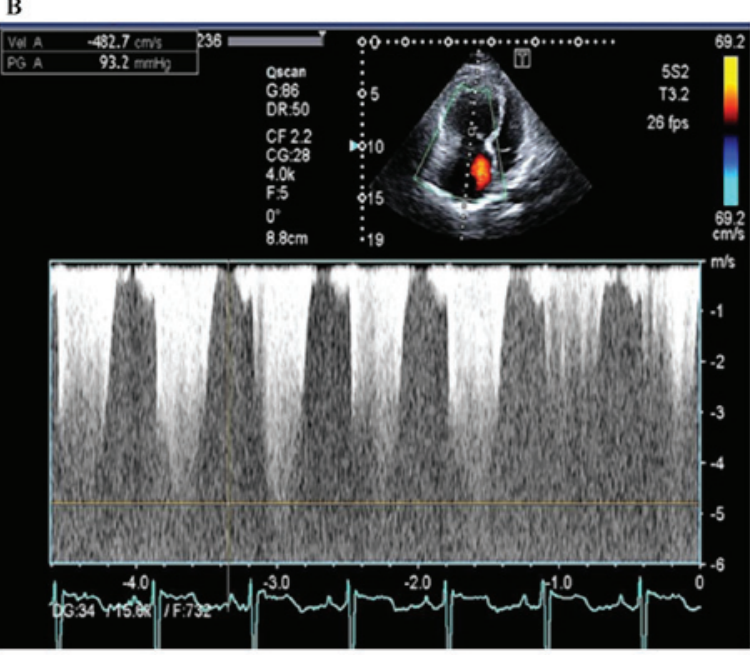

Figure 3. Echocardiography performed on a 36-year-old female with pulmonary hypertension. (A) Tricuspid regurgitation Vel was $415.9 \mathrm{~cm} / \mathrm{sec}$ and the PG was $69.2 \mathrm{mmHg}$. (B) Contrasted echocardiography of the right side of the heart revealed a tricuspid regurgitation Vel of $482.7 \mathrm{~cm} / \mathrm{sec}$ with a PG of $93.2 \mathrm{mmHg}$. Vel, velocity; PG, pressure gradient.
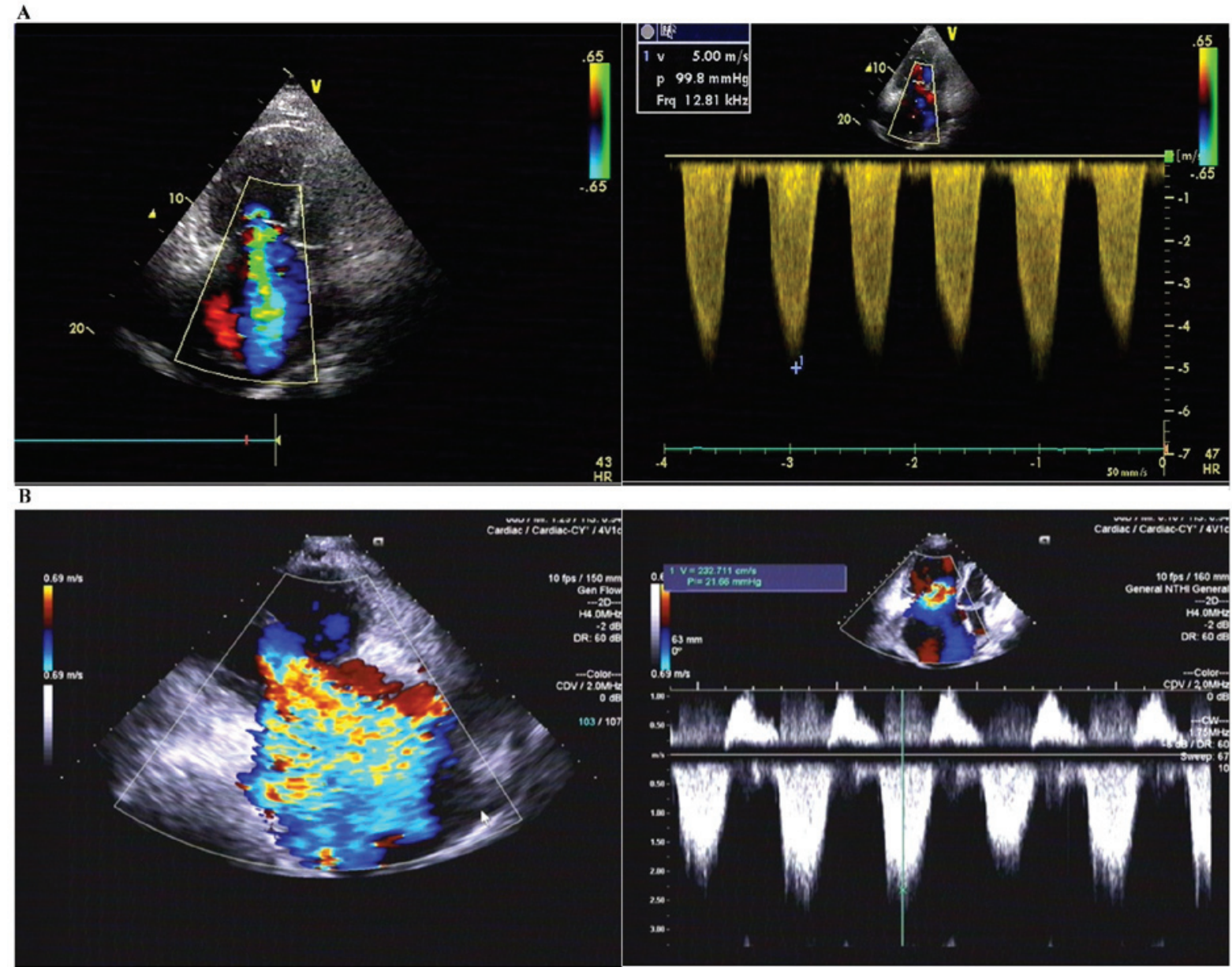

Figure 4. Echocardiography performed on a 61-year-old female with pulmonary hypertension. (A) Echocardiography revealed intermediate to severe tricuspid regurgitation with a Vel of $500 \mathrm{~cm} / \mathrm{sec}$ and a PG of $99.8 \mathrm{mmHg}$ in August 2011. (B) Echocardiography, performed 3 years later, revealed severe tricuspid regurgitation with a Vel of $232 \mathrm{~cm} / \mathrm{sec}$ and a PG of $21.6 \mathrm{mmHg}$. Vel, velocity; PG, pressure gradient.

remains low $(34,35)$. Thus, SPAP measurements using echocardiography should be performed at the end of inspiration or at the end of expiration whilst the patient holds their breath.
This may avoid the inaccuracy of overestimation or underestimation. Right atrium pressure also affects the accuracy of SPAP measurement. In the patients included in the the present 

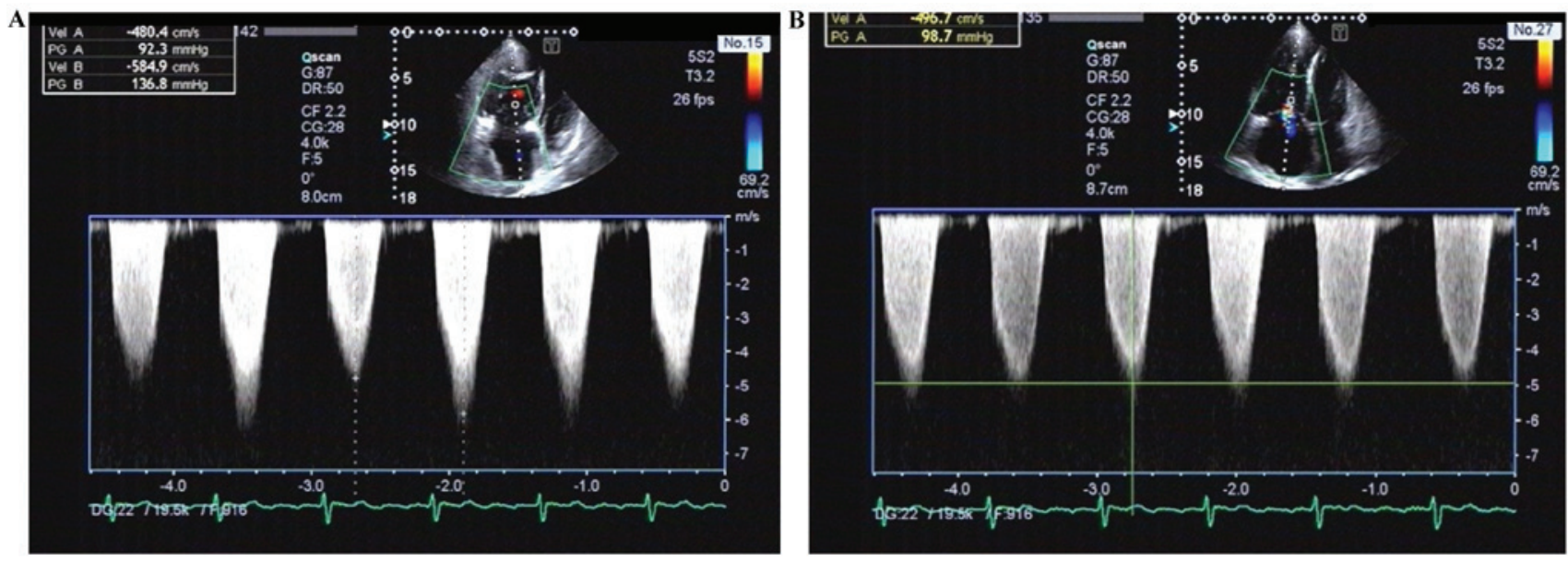

Figure 5. Echocardiography performed on a 33-year-old male with pulmonary hypertension. (A) During inspiration, tricuspid regurgitation Vel was $480.4 \mathrm{~cm} / \mathrm{sec}$ with a PG of $92.3 \mathrm{mmHg}$. During expiration, tricuspid regurgitation Vel was $584.9 \mathrm{~cm} / \mathrm{sec}$ with a PG of $136.8 \mathrm{mmHg}$. (B) At the end of expiration, tricuspid regurgitation Vel was $496.7 \mathrm{~cm} / \mathrm{sec}$ with a $\mathrm{PG}$ of $98.7 \mathrm{mmHg}$. Vel, velocity; PG, pressure gradient.

study, the mean CVP was $6.38 \pm 5.12 \mathrm{mmHg}$, suggesting that overestimation of right atrium pressure may be a reason for the overestimation of SPAP. In addition, it has been demonstrated that increased right atrium pressure is associated with patient prognosis in PAH (36). Therefore, the accurate measurement of right atrium pressure is important in the diagnosis and prognosis of $\mathrm{PH}$.

The present study demonstrated that only TAPSE and CVP measurements were significantly different between the groups with overestimation or underestimation of SPAP by echocardiography. It has been suggested that right-sided heart function is not a dominant factor affecting SPAP; however, it may affect the accuracy of the measurement $(30,35)$. A previous meta-analysis revealed that the correlation coefficient between SPAP measurements obtained using Doppler echocardiography and those obtained using RHC ranged from 0.65-0.97, and that the sensitivity, specificity and diagnostic accuracy of Doppler echocardiography was 88,56 and $63 \%$, respectively (37). The present study indicated that non-invasive echocardiography is a reliable method for the classification of normal, increased and significantly increased pulmonary arterial pressure. However, measurement results of echocardiography should be verified by using RHC. A study by Greiner et al (38) indicated that near simultaneous Doppler echocardiography examinations within $24 \mathrm{~h}$ demonstrated a closer correlation compared with examinations with an interval of $>24 \mathrm{~h}$. In addition, Doppler echocardiography examinations that were performed prior to RHC were more correlated compared with those performed after RHC (38).

The primary limitation of the present study was the small sample size. Further studies using a larger cohort are required to investigate the application of echocardiography in different pathologic groups, such as PAH and chronic thromboembolic pulmonary hypertension. Right heart catheterization parameters in the normal control group require further study. Another limitation of the current study was that the SPAP measured by echocardiography and RHC were not conducted simultaneously.

In conclusion, the present study demonstrated that SPAP measured using echocardiography is significantly positively correlated with SPAP measured using RHC, and that only TAPSE and CVP measurements were significantly between patient with $\mathrm{PH}$ patients with overestimation and underestimation of SPAP by echocardiography. However, due to the small sample size used, further investigations are required to determine the specific reasons for the overestimation or underestimation of SPAP measurement by echocardiography.

\section{Acknowledgements}

The present study was supported by the National Natural Science Foundation of China (grant no. 81401420), the Fund of Beijing Excellent Talent Training Plan (grant no. 2013D003034000012) and the Fund of Beijing Health System High Level Health Technology Personnel Discipline Backbone Project (grant no. 2014-3-027).

The abstract of the present study was presented at the Meeting of the CHEST World Congress 2016 April 16, 2016 in Shanghai, and published as abstract in Chest 149(4S):A516. 2016.

\section{References}

1. Low AT, Medford AR, Millar AB and Tulloh RM: Lung function in pulmonary hypertension. Respir Med 109: 1244-1249, 2015.

2. Kholdani CA and Fares WH: Management of right heart failure in the intensive care unit. Clin Chest Med 36: 511-520, 2015.

3. Bourji KI and Hassoun PM: Right ventricle dysfunction in pulmonary hypertension: Mechanisms and modes of detection. Curr Opin Pulm Med 21: 446-453, 2015.

4. Galiè N, Humbert M, Vachiery JL, Gibbs S, Lang I Torbicki A, Simonneau G, Peacock A, Vonk Noordegraaf A, Beghetti M, et al: 2015 ESC/ERS Guidelines for the diagnosis and treatment of pulmonary hypertension: The joint task force for the diagnosis and treatment of pulmonary hypertension of the European society of cardiology (ESC) and the European respiratory society (ERS): Endorsed by: Association for European paediatric and congenital cardiology (AEPC), International society for heart and lung transplantation (ISHLT). Eur Heart J 37: 67-119, 2016.

5. Hassoun PM: Inflammation in chronic thromboembolic pulmonary hypertension: Accomplice or bystander in altered angiogenesis? Eur Respir J 46: 303-306, 2015. 
6. Kang KY, Jeon CH, Choi SJ, Yoon BY, Choi CB, Lee CH, Suh CH, Lee CW, Cho CS, Nam EJ, et al: Survival and prognostic factors in patients with connective tissue disease-associated pulmonary hypertension by echocardiography: Results from a Korean nationwide registry. Int J Rheum Dis: Jul 27, 2015 (Epub ahead of print).

7. Lundgren $J$ and Rådegran G: Hemodynamic characteristics including pulmonary hypertension at rest and during exercise before and after heart transplantation. J Am Heart Assoc 4 e001787, 2015 .

8. Raghu G, Nathan SD, Behr J, Brown KK, Egan JJ, Kawut SM, Kawut SM, Flaherty KR, Martinez FJ, Wells AU, et al: Pulmonary hypertension in idiopathic pulmonary fibrosis with mild-to-moderate restriction. Eur Respir J 46: 1370-1377, 2015.

9. Zakir RM, Al-Dehneh A, Maher J, Saric M and Berkowitz RL: Right ventricular failure in patients with preserved ejection fraction and diastolic dysfunction: An underrecognized clinical entity. Congest Heart Fail 13: 164-169, 2007.

10. Raeisi-Giglou P, Lam L, Tamarappoo BK, Newman J, Dweik RA and Tonelli AR: Evaluation of left ventricular diastolic function profile in patients with pulmonary hypertension due to heart failure with preserved ejection fraction. Clin Cardiol: Dec 27, 2016 (Epub ahead of print).

11. Shah S, Boyd G, Pyne CT, Bilazarian SD, Piemonte TC, Jeon C and Waxman S: Right heart catheterization using antecubital venous access: Feasibility, safety and adoption rate in a tertiary center. Catheter Cardiovasc Interv 84: 70-74, 2014.

12. Di Maria MV, Burkett DA, Younoszai AK, Landeck BF II, Mertens L, Ivy DD, Friedberg MK and Hunter KS Echocardiographic estimation of right ventricular stroke work in children with pulmonary arterial hypertension: Comparison with invasive measurements. J Am Soc Echocardiogr 28: 1350-1357, 2015

13. Bane O, Shah SJ, Cuttica MJ, Collins JD, Selvaraj S, Chatterjee NR, Guetter C, Carr JC and Carroll TJ: A non-invasive assessment of cardiopulmonary hemodynamics with MRI in pulmonary hypertension. Magn Reson Imaging 33: 1224-1235, 2015.

14. Pektas A, Olgunturk R, Cevik A, Terlemez S, Kacar E and Oner YA: Magnetic resonance imaging in pediatric pulmonary hypertension. Tex Heart Inst J 42: 209-215, 2015.

15. Tadic M: Multimodality evaluation of the right ventricle: An updated review. Clin Cardiol 38: 770-776, 2015.

16. Creuzé N, Hoette S, Montani D, Gunther S, Lau E, Ternacle J, Savale L, Jaïs X, Parent F, Girerd B, et al: Usefulness of cardiovascular magnetic resonance indices to rule in or rule out precapillary pulmonary hypertension. Can J Cardiol 31: 1469 , 2015.

17. Tatebe S, Fukumoto Y, Oikawa-Wakayama M, Sugimura K Satoh K, Miura Y, Aoki T, Nochioka K, Miura M, Yamamoto $\mathrm{S}$, et al: Enhanced [18F]fluorodeoxyglucose accumulation in the right ventricular free wall predicts long-term prognosis of patients with pulmonary hypertension: A preliminary observational study. Eur Heart J Cardiovasc Imaging 15 : 666-672, 2014

18. Ahmadi A, Ohira H and Mielniczuk LM: FDG PET imaging for identifying pulmonary hypertension and right heart failure. Curr Cardiol Rep 17: 555, 2015.

19. Yang T, Wang L, Xiong CM, He JG, Zhang Y, Gu Q, Zhao ZH, Ni XH, Fang W and Liu ZH: The ratio of (18)F-FDG activity uptake between the right and left ventricle in patients with pulmonary hypertension correlates with the right ventricular function. Clin Nucl Med 39: 426-430, 2014

20. Lang IM, Plank C, Sadushi-Kolici R, Jakowitsch J, Klepetko W and Maurer G: Imaging in pulmonary hypertension. JACC Cardiovasc Imaging 3: 1287-1295, 2010.

21. Vitarelli A and Gheorghiade M: Transthoracic and transesophageal echocardiography in the hemodynamic assessment of patients with congestive heart failure. Am J Cardiol 86: 36G-40G, 2000

22. Sohrabi B, Kazemi B, Mehryar A, Teimouri-Dereshki A, Toufan M and Aslanabadi N: Correlation between pulmonary artery pressure measured by echocardiography and right heart catheterization in patients with rheumatic mitral valve stenosis (A Prospective Study). Echocardiography 33: 7-13, 2016.

23. Naeije R, D'Alto M and Forfia PR: Clinical and research measurement techniques of the pulmonary circulation: The present and the future. Prog Cardiovasc Dis 57: 463-472, 2015.
24. Rich JD: Rebuttal from Dr Rich. Chest 143: 1540-1541, 2013

25. Rudski LG: Rebuttal from Dr Rudski. Chest 143: 1539-1540, 2013.

26. Rich JD: Counterpoint: Can Doppler echocardiography estimates of pulmonary artery systolic pressures be relied upon to accurately make the diagnosis of pulmonary hypertension? No. Chest 143: 1536-1539, 2013

27. Lang RM, Badano LP, Mor-Avi V, Afilalo J, Armstrong A, Ernande L, Flachskampf FA, Foster E, Goldstein SA, Kuznetsova T, et al: Recommendations for cardiac chamber quantification by echocardiography in adults: An update from the American society of Echocardiography and the European association of cardiovascular imaging. J Am Soc Echocardiogr 28: 1-39.e14, 2015

28. McLaughlin VV, Archer SL, Badesch DB, Barst RJ, Farber HW, Lindner JR, Mathier MA, McGoon MD, Park MH, Rosenson RS, et al: ACCF/AHA 2009 expert consensus document on pulmonary hypertension: A report of the American college of cardiology foundation task force on expert consensus documents and the American heart association: developed in collaboration with the American college of chest physicians, American thoracic society, Inc. and the Pulmonary Hypertension association. Circulation 119: 2250-2294, 2009.

29. Galie N, Humbert M, Vachiery JL, Gibbs S, Lang I, Torbicki A, Simonneau G, Peacock A, Vonk Noordegraaf A, Beghetti M, et al: 2015 ESC/ERS guidelines for the diagnosis and treatment of pulmonary hypertension: The joint task force for the diagnosis and treatment of pulmonary hypertension of the European society of cardiology (ESC) and the European Respiratory Society (ERS): Endorsed by: Association for European paediatric and congenital cardiology (AEPC), International society for heart and lung transplantation (ISHLT). Eur Respir J 46: 903-975, 2015.

30. Finkelhor RS, Lewis SA and Pillai D: Limitations and strengths of doppler/echo pulmonary artery systolic pressure-right heart catheterization correlations: A systematic literature review. Echocardiography 32: 10-18, 2015.

31. Rudski LG, Lai WW, Afilalo J, Hua L, Handschumacher MD, Chandrasekaran K, Solomon SD, Louie EK and Schiller NB: Guidelines for the echocardiographic assessment of the right heart in adults: A report from the American society of Echocardiography endorsed by the European association of Echocardiography, a registered branch of the European society of cardiology, and the canadian society of echocardiography. J Am Soc Echocardiogr 23: 685-713, 2010.

32. Jeon DS, Luo H, Iwami T, Miyamoto T, Brasch AV, Mirocha J, Naqvi TZ and Siegel RJ: The usefulness of a $10 \%$ air- $10 \%$ blood $-80 \%$ saline mixture for contrast echocardiography: Doppler measurement of pulmonary artery systolic pressure. J Am Coll Cardiol 39: 124-129, 2002.

33. Domenighetti G: Prognosis, screening, early detection and differentiation of arterial pulmonary hypertension. Swiss Med Wkly 137: 331-336, 2007

34. Topilsky Y, Tribouilloy C, Michelena HI, Pislaru S, Mahoney DW and Enriquez-Sarano M: Pathophysiology of tricuspid regurgitation: Quantitative Doppler echocardiographic assessment of respiratory dependence. Circulation 122: 1505-1513, 2010.

35. Huttin O, Voilliot D, Mandry D, Venner C, Juillière $Y$ and Selton-Suty C: All you need to know about the tricuspid valve: Tricuspid valve imaging and tricuspid regurgitation analysis. Arch Cardiovasc Dis 109: 67-80, 2016.

36. Austin C, Alassas K, Burger C, Safford R, Pagan R, Duello K, Kumar P,Zeiger T and Shapiro B: Echocardiographic assessment of estimated right atrial pressure and size predicts mortality in pulmonary arterial hypertension. Chest 147: 198-208, 2015.

37. Taleb M, Khuder S, Tinkel J and Khouri SJ: The diagnostic accuracy of Doppler echocardiography in assessment of pulmonary artery systolic pressure: A meta-analysis. Echocardiography 30: 258-265, 2013.

38. Greiner S, Jud A, Aurich M, Hess A, Hilbel T, Hardt S, Katus HA and Mereles D: Reliability of noninvasive assessment of systolic pulmonary artery pressure by Doppler echocardiography compared to right heart catheterization: Analysis in a large patient population. J Am Heart Assoc 3: e001103, 2014. 